\title{
Molecular structure and vibrational spectra of methyl cyanoacetate: an FT-IR, raman and ab initio molecular orbital study
}

\author{
João Miguel F. Neta, Rui Fausto* \\ Departamento de Quimica, Universidade de Coimbra, P-3049 Coimbra, Portugal
}

Received 6 August 1997; revised 15 September 1997; accepted 15 September 1997

\begin{abstract}
The results of a combined vibrational and structural study of methyl cyanoacetate undertaken by Raman and infrared spectroscopy, and ab initio SCF-MO calculations are presented. It is shown that for the isolated molecule situation, as well as in the liquid phase, methyl cyanoacetate exists as a mixture of two main conformers of similar energies, differing by the relative orientation of the $\mathrm{NC}-\mathrm{C}-\mathrm{C}=\mathrm{O}$ axis (the syn and skew forms, having a $\mathrm{NC}-\mathrm{C}-\mathrm{C}=\mathrm{O}$ dihedral angle equal to $0^{\circ}$ and in the $\pm 140^{\circ}$ region, respectively). In the crystalline state, only the thermodynamically most stable syn conformer remains. The ab initio SCF-MO optimized geometries of the various possible conformers, their relative stabilities, dipole moments and harmonic force-fields are presented, and the conformational dependence of some relevant structural parameters is used to characterise the most important intramolecular interactions present in the various forms studied. Finally, results of a normal mode analysis based on the ab initio calculated vibrational spectra are used to help interpret the experimental vibrational data, enabling a detailed assignment of both Raman and infrared spectra. (C) 1998 Elsevier Science B.V.
\end{abstract}

Keywords: Methyl cyanoacetate; Molecular structure; Infrared spectrum; Raman spectrum; Molecular orbital calculations

\section{Introduction}

Methyl cyanoacetate $\left[\mathrm{N} \equiv\left(\mathrm{CCH}_{2} \mathrm{C}(=\mathrm{O}) \mathrm{OCH}_{3}\right.\right.$; $\mathrm{MCA}$ ] is currently used both as an intermediate in pharmaceutically oriented synthetic chemistry and as a starting material for the industrial production of some herbicides and bactericides [1]. However, despite its relevant industrial importance, this compound has not been deserved much attention in the past. The first study dealing with the conformational isomerim in MCA was published almost 20 years ago [2]. In that study, a first attempt was made to interpret the infrared spectra of liquid and crystalline MCA, as

\footnotetext{
* Corresponding author
}

well as those obtained for this molecule in $\mathrm{CCl}_{4}$ or $\mathrm{CS}_{2}$ diluted solutions, in terms of the presence of two relevant conformational states (the syn form, where the $\mathrm{NC}-\mathrm{C}-\mathrm{C}=\mathrm{O}$ dihedral angle is equal to $0^{\circ}$, and the skew conformer, where this angle should be close to $\pm 120^{\circ}$; in both cases the ester group was assumed to adopt the $s$-cis conformation, Fig. 1). The syn conformer was assumed to be the most stable form in all phases studied, and the energy difference between the two conformers estimated to be $4.06 \mathrm{~kJ}$ $\mathrm{mol}^{-1}$, in the pure liquid (in the crystal only the bands ascribed to the most stable form could be observed) [2]. More recently, however, the conformational equilibrium of MCA was reinvestigated by a combined infrared spectroscopy and P.C.I.L.O. theoretical 


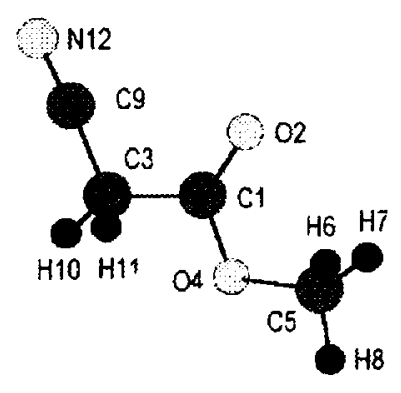

syn/s-cis.

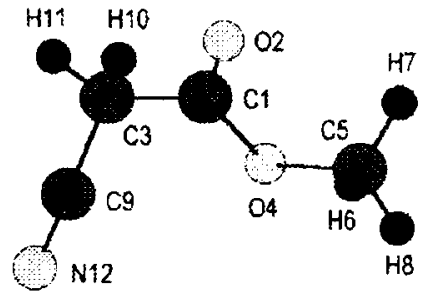

skew/s-cis.

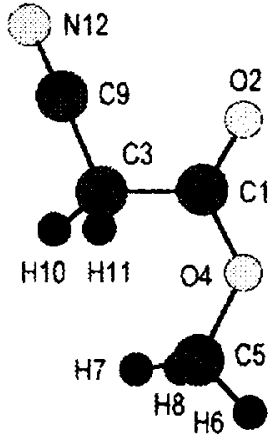

syn/s-trans.

Fig. 1. Conformers of methyl cyanoacetate and atom numbering scheme. The two $s$-cis forms correspond to the two single conformers considered in all previous studies of MCA [2-4].

approach [3], and the relative energy of the two observed conformers was estimated to be considerably lower than that previously reported $\left(\Delta E_{s k e w-s y n}=\right.$ $1.46 \mathrm{~kJ} \mathrm{~mol}^{-1}$ [3]). In addition, the P.C.I.L.O. calculations predicted the skew form as the ground conformational state for the isolated molecule situation $\left(\Delta E_{\text {skew-syn }}=-2.13 \mathrm{~kJ} \mathrm{~mol}^{-1}[3,4]\right)$.

In all previous studies [2-4], however, neither the evaluation of precise molecular geometries of the different possible conformers of MCA nor a detailed analysis of the vibrational spectra of this molecule were undertaken. Moreover, it appeared to be essential, in order to enable the establishment of fundamental structure/spectra correlations and to evaluate the most relevant intramolecular interactions present in the various conformers of methyl cyanoacetate, that this molecule should be the subject of a systematic structural and vibrational study by means of a higher level theoretical approach. Thus, in order to fill this gap, in this article we report the results of a combined vibrational spectroscopy (Raman and infrared) and ab initio SCF-MO study carried out on MCA.

\section{Experimental and computational methods}

Spectroscopic grade methyl cyanoacetate $(99.9 \%)$ was obtained from Aldrich and purified by conventional methods prior to spectra recording.

Infrared spectra were obtained using a Nicolet FTIR 800 system equipped for the $4000-400 \mathrm{~cm}^{-1}$ region with a germanium on CsI beam splitter and a deuterated triglycine sulphide (DTGS) detector with CsI windows. Data collection was performed using a specially designed demountable transmission variable temperature liquid cell with $\mathrm{KBr}$ windows, linked to a VENTACON (Winchester) model CAL 9000 temperature controller. For each spectrum 32 scans were recorded with the spectral resolution $1 \mathrm{~cm}^{-1}$ and coadded. 
Raman spectra were obtained using a modified Harney-Miller variable temperature sampling system in a SPEX 1403 double monochromator spectrometer (focal distance $0.85 \mathrm{~m}$, aperture/7.8), equipped with holographic gratings with 1800 grooves $\mathrm{mm}^{-1}$ (ref. 1800-1SHD). The $514.5 \mathrm{~nm}$ argon laser (SpectraPhysics, model 164-05) line, adjusted to provide $220 \mathrm{~mW}$ power at the sample, was used as excitation radiation. Detection was effected using a thermoelectrically cooled Hamamatsu R928 photomultiplier. Spectra were recorded using increments of $1 \mathrm{~cm}^{-1}$ and integration times of $1 \mathrm{~s}$. Under these conditions, the estimated errors in wavenumbers are $1 \mathrm{~cm}^{-1}$.

The ab initio molecular orbital calculations were performed using the $6-31 \mathrm{G}^{*}$ basis set [5] with the GAUSSIAN92/DFT program package [6] running on a DEC ALPHA 7000 computer. Molecular geometries were fully optimised by the force gradient method using Berny's algorithm [7]. The largest residual coordinate forces were always less than $3 \times$ $10^{-4}$ hartree $\mathrm{bohr}^{-1}\left(1\right.$ hartree $=2625.5001 \mathrm{~kJ} \mathrm{~mol}^{-1}$; I bohr $=5.29177 \times 10^{-11} \mathrm{~m}$ ) or hartree $\mathrm{rad}^{-1}$, for bond stretches and angle bends, respectively. The stopping criterion for the SCF iterative process required a density matrix convergence of less than $10^{-8}$. The force constants (symmetry internal coordinates) to be used in the normal coordinate analysis were obtained from the $\mathrm{ab}$ initio cartesian harmonic force constants using the program TRANSFORMER (version 2.0) [8]. This program was also used to prepare the input data for the normal coordinate analysis programs used in this study (BUILD-G and VIBRAT [9]).

\section{Results and discussion}

\subsection{Geometries and relative energies}

Methyl cyanoacetate has two internal axes of rotation that can lead to conformational isomers. These correspond to rotations about the $\mathrm{Cl}-\mathrm{O} 4$ and $\mathrm{Cl}-\mathrm{C} 3$ bonds. On the other hand, the preferred orientation of the ester group in methyl esters is well known to be that where one of the hydrogen atoms stands in the anti periplanar position relative to the carbonyl carbon atom [10-12] (Fig. 1).

Conformational isomerism about the $\mathrm{C}-\mathrm{O}$ single bond in carboxylic acids and esters has been studied in detail previously [10-14]. It is now well established that these compounds adopt preferentially the $s$-cis conformation about this bond $(\mathrm{O}=\mathrm{C}-\mathrm{O}-R$ dihedral angle equals to $0 ; R=\mathrm{H}$ or alkyl), except when strong steric hindrance dominates. The energy difference between this conformation and the second stable form (the s-trans conformer, corresponding to a $\mathrm{O}=\mathrm{C}-\mathrm{O}-R$ dihedral angle equal to $180^{\circ}$ ) and the energy barrier for interconversion between these two forms are usually very large (over 20 and $40 \mathrm{~kJ} \mathrm{~mol}^{-1}$, respectively $[10-16])$. The main factors which determine the much lower energy of the $s$-cis $\mathrm{O}=\mathrm{C}-\mathrm{O}-R$ axis when compared with that of the $s$-trans $\mathrm{O}=\mathrm{C}-\mathrm{O}-$ $R$ axis are the presence in the first of the strongly stabilising through-space field interaction resulting from the nearly antiparallel alignment of the $\mathrm{C}=\mathrm{O}$ and $\mathrm{O}-R$ bond dipoles, and the destabilising steric interactions between the $R$ group and the acyl fragment in the $s$-trans form [13]. In general, $s$-trans conformers are not observed spectroscopically under current experimental conditions, unless particular specific intramolecular stabilising interactions are operating (e.g. intramolecular hydrogen bonding in chloroacetic acid monomer [16,17]). However, $s$-trans-like conformations have been recently proposed as catalytically important conformational states [18], thus justifying the interest in studying $s$-trans conformational states of carboxylic compounds as well.

The conformational isomerism in $\alpha$-substituted carbonyl compounds related with the internal rotation about the bond made by the $\alpha$ and the carbonyl carbon atoms $\left(\mathrm{C}_{\alpha}-\mathrm{C}\right)$ is associated, in general, with relatively low energy barriers and conformer energy differences, and has been extensively studied in our laboratory for a series of different $\alpha$-carbon substituents $[12,13,15,16]$. In the case of alkyl esters adopting the $s$-cis conformation about the $\mathrm{C}-\mathrm{O}$ bond, the internal rotation about the $\mathrm{C}_{\alpha}-\mathrm{C}$ bond in mono-substituted compounds originates two different, by symmetry, conformers (the syn and skew forms, Fig. 1) whose relative energy difference is in general quite small $[12,13,15,19,20]$. Most of the time, the $C_{5}$ symmetry syn conformer is slightly more stable than the doubly degenerated by symmetry $\mathrm{C}_{1}$ skew form, in particular when the $\alpha$-substituents are relatively volumous or electronegative $[10,12,20]$. For s-trans $(C-O)$-like ester molecules, the appearance of stable conformations having a non-planar skeleton is common, which 
essentially result from the strong steric interactions between the alkyl ester moiety and the acyl group $[10,12,20]$. The main factors responsible for the relative stabilities of the conformations interconvertible by internal rotation about the $\mathrm{C}_{\alpha}-\mathrm{C}$ bond in carboxylic compounds have been discussed in detail elsewhere $[10,12,19,20]$, being essentially due to (i) the larger effective volume and more negative charge of the $\mathrm{O}$ - atom when compared with the carbonyl oxygen, (ii) several specific electronic effects that, besides depending upon the properties of the carboxylic group, also depend on the nature of the substituent (mesomerism $[13,15]$, hyperconjugation $[19,20]$, interfragment HOMO/LUMO interactions $[10,19]$ ), and (iii) intramolecular hydrogen bonding $[12,16,19]$.

The theoretical calculations undertaken in this study were able to identify four distinct conformers of MCA (Fig. 1). The calculated geometries and relative energies of these conformers are presented in Table 1. As expected, the conformers having an

Table 1

6-31G* calculated optimised geometries and energies for the various conformers of methyl cyanoacetate

\begin{tabular}{|c|c|c|c|c|}
\hline Parameter $^{\mathrm{a}}$ & $\begin{array}{l}\text { Conformer } \\
\text { syn/s-cis }\end{array}$ & syn/s-trans & skew/s-cis & skew/s-trans \\
\hline & \multicolumn{4}{|c|}{ bond length/pm } \\
\hline $\mathrm{ClO} 2$ & 118.23 & 117.79 & 118.50 & 118.04 \\
\hline $\mathrm{ClC} 3$ & 151.71 & 152.64 & 151.97 & 153.17 \\
\hline $\mathrm{ClO} 4$ & 131.93 & 132.70 & 131.31 & 132.19 \\
\hline $\mathrm{O} 4 \mathrm{C} 5$ & 142.16 & 141.02 & 142.21 & 141.52 \\
\hline $\mathrm{C} 5 \mathrm{H} 6$ & 107.99 & 107.80 & 107.97 & 107.78 \\
\hline $\mathrm{C} 5 \mathrm{H} 7$ & 107.99 & 108.28 & 107.99 & 108.00 \\
\hline $\mathrm{C} 5 \mathrm{H} 8$ & 107.79 & 108.28 & 107.75 & 108.27 \\
\hline $\mathrm{C} 3 \mathrm{C} 9$ & 146.68 & 146.63 & 146.89 & 147.02 \\
\hline $\mathrm{C} 3 \mathrm{H} 10$ & 108.36 & 108.39 & 108.51 & 108.36 \\
\hline $\mathrm{C} 3 \mathrm{HII}$ & 108.36 & 108.39 & 108.03 & 107.97 \\
\hline $\mathrm{C} 9 \mathrm{~N} 12$ & $\begin{array}{l}113.36 \\
\text { bond angle }\end{array}$ & \multicolumn{2}{|c|}{ bond angle/degrees } & 113.43 \\
\hline $\mathrm{C} 3 \mathrm{ClO} 2$ & 125.53 & 122.85 & 122.53 & 120.23 \\
\hline $\mathrm{O} 2 \mathrm{ClO} 4$ & 125.03 & 120.62 & 125.14 & 120.75 \\
\hline $\mathrm{C} 3 \mathrm{ClO} 4$ & 109.43 & 116.52 & 112.32 & 119.01 \\
\hline $\mathrm{ClO} 4 \mathrm{C} 5$ & 116.90 & 124.05 & 117.23 & 124.31 \\
\hline O4C5H6 & 110.28 & 105.58 & 110.19 & 105.30 \\
\hline $\mathrm{O} 4 \mathrm{C} 5 \mathrm{H} 7$ & 110.28 & 111.60 & 110.21 & 111.45 \\
\hline $\mathrm{O} 4 \mathrm{C} 5 \mathrm{H} 8$ & 105.67 & 111.60 & 105.60 & 111.32 \\
\hline $\mathrm{ClC} 3 \mathrm{C} 9$ & 113.19 & 112.34 & 114.16 & 113.30 \\
\hline $\mathrm{C} 1 \mathrm{C} 3 \mathrm{H} 10$ & 108.79 & 110.13 & 107.92 & 111.14 \\
\hline $\mathrm{C} 1 \mathrm{C} 3 \mathrm{H} 11$ & 108.79 & 110.13 & 108.16 & 106.40 \\
\hline C $3 \mathrm{C} 9 \mathrm{~N} 12$ & $\begin{array}{l}182.46 \\
\text { dihedral an }\end{array}$ & \multicolumn{2}{|c|}{ dihedral angle/degrees } & 180.22 \\
\hline $\mathrm{O} 4 \mathrm{C} 3 \mathrm{C} 1 \mathrm{O} 2$ & 180.00 & 180.00 & 177.15 & 179.00 \\
\hline $\mathrm{C} 5 \mathrm{O} 4 \mathrm{C} 1 \mathrm{C} 3$ & 180.00 & 0.00 & 178.98 & 3.92 \\
\hline $\mathrm{H} 6 \mathrm{C} 5 \mathrm{O} 4 \mathrm{Cl}$ & 60.53 & 180.00 & 59.61 & 175.23 \\
\hline $\mathrm{H} 7 \mathrm{C} 5 \mathrm{O} 4 \mathrm{Cl}$ & 60.53 & 61.76 & 61.48 & 66.25 \\
\hline $\mathrm{H} 8 \mathrm{C} 5 \mathrm{O} 4 \mathrm{Cl}$ & 180.00 & 61.76 & 179.02 & 57.35 \\
\hline $\mathrm{C} 9 \mathrm{C} 3 \mathrm{ClO} 2$ & 0.00 & 0.00 & 141.02 & 114.03 \\
\hline $\mathrm{H} 10 \mathrm{C} 3 \mathrm{C} 1 \mathrm{O} 2$ & 121.95 & 121.11 & 98.38 & 123.37 \\
\hline $\mathrm{H} 1 \mathrm{CC} 3 \mathrm{ClO} 2$ & \multicolumn{4}{|c|}{ conformer energy $/ \mathrm{kJ} \mathrm{mol}^{-1}$} \\
\hline$\Delta E^{\mathrm{b}}$ & 0.00 & 45.99 & 0.94 & 44.40 \\
\hline
\end{tabular}

${ }^{a}$ See Fig. 1 for atom numbering.

${ }^{b}$ Energies relative to the most stable conformer; values presented include zero-point vibrational energy corrections. The total energy for the most stable form is, $-358.5616241\left(E_{\mathrm{h}}\right)$. 
s-cis $(\mathrm{C}-\mathrm{O})$ axis are considerably more stable than the s-trans forms. In addition, for a given conformation of the $\mathrm{C}-\mathrm{O}$ axis, the two conformers differing in the orientation of the cyano group relative to the carbonyl group (syn and skew forms) have similar energies. Contrary to the results previously obtained by using the P.C.I.L.O. method [3,4], the higher level ab initio calculations predict the $s y n / s$-cis form as corresponding to the conformational ground state for the isolated molecule situation (the zero-point-energy corrected $\Delta E_{(\text {skew:s-ciss)-(sin's-cis) }}$ energy difference was found to be $0.94 \mathrm{~kJ} \mathrm{~mol}^{-1}$; Table 1). Essentially, the slightly higher energy of the skew/s-cis form when compared with the syn/s-cis conformer results from the more important repulsive interactions between the cyano group (that has a relatively large electron density due to its triple bond) and the lone-electron pairs of the ester oxygen, that is both more negatively charged and more volumous than the carbonyl oxygen $[11,12,20]$. These stronger cyano/ $-\mathrm{O}-$ repulsions in the skew/s-cis form when compared with the cyano/ $\mathrm{O}=$ repulsions are clearly reflected in the longer $\mathrm{C} \equiv \mathrm{N}$, $\mathrm{C}_{\alpha}-\mathrm{C}$ and $\mathrm{O}-\mathrm{C}\left(\mathrm{H}_{3}\right)$ bond lengths, and in the larger $\mathrm{C}-\mathrm{C}-\mathrm{C}, \mathrm{C}-\mathrm{C}-\mathrm{O}$ and $\mathrm{C}-\mathrm{O}-\mathrm{C}$ angles found in the skew/s-cis form (Table 1). On the other hand, in the case of the two high energy s-trans $(\mathrm{C}-\mathrm{O})$ conformers, the syn form about the $\mathrm{C}_{\alpha}-\mathrm{C}$ axis is less stable than the skew form by ca. $1.6 \mathrm{~kJ} \mathrm{~mol}^{-1}$. This relative destabilisation of the syn conformation about the $\mathrm{C}_{\alpha-}$ $\mathrm{C}$ axis associated with the change in conformation about the $\mathrm{C}-\mathrm{O}$ bond can be easily explained considering the extra repulsive interactions due to the close proximity of the two methylene hydrogen atoms from the two out-of-plane methyl hydrogens in the $s y n / s-$ trans conformer, that have no counterpart either in the $s y n / s$-cis or in the skew/s-trans forms (Fig. 1). In addition, the possible existence of a weak intramolecular hydrogen bond involving one of the methyl hydrogens and the $\mathrm{C} \equiv \mathrm{N}$ triple bond in the skew/s-trans form may also contribute to the observed inversion of the syn $\left(\mathrm{C}_{\alpha}-\mathrm{C}\right)$ versus skew $\left(\mathrm{C}_{\alpha}-\mathrm{C}\right)$ axis stability upon changing from the $s$-cis to the $s$-trans $(\mathrm{C}-\mathrm{O})$ configuration, though the above mentioned repulsive interaction is certainly the most important factor. A similar hydrogen bond interaction, but that time involving the considerably stronger $\mathrm{OH} / \mathrm{C} \equiv \mathrm{N}$ intramolecular hydrogen bond, was found to operate in the monomer of cyanoacetic acid, being the most important factor in stabilizing the anti/s-trans conformer of this molecule relative to the syn/s-trans form [1].

In general, the changes in geometric parameters with the $s$-cis $\rightarrow$ s-trans isomerisation follow the typical pattern of variation for these kind of systems $[10-16]$ and do not require here any additional comments: e.g. the $\mathrm{C}=\mathrm{O}$ bond length reduces while the $\mathrm{C}-$ $\mathrm{O}$ bond length increases, due to the reduced importance in the $s$-trans forms of the mesomerism associated with the ester group, the $\mathrm{O}=\mathrm{C}-\mathrm{O}$ and $\mathrm{C}-\mathrm{O}-\mathrm{C}$ angles reduce, since in the $s$-cis forms the molecular heavy atom backbone must open to make way for the methyl group. In turn, besides the structural changes already referred to above that originate in the different strengths of the cyano/ $-\mathrm{O}-$ and cyano $/ \mathrm{O}=$ repulsions, the syn $\rightarrow$ skew isomerization about the $\mathrm{C}_{\alpha}-\mathrm{C}$ bond does not lead to any additional relevant change in the geometric parameters, though the $\mathrm{C}=\mathrm{O}$ bond length is slightly longer in skew than in syn conformers (Table 1). This slight increase in the $\mathrm{C}=\mathrm{O}$ bond length may be explained, at least in part, considering that the closest proximity of the positively charged methylene hydrogens from the carbonyl oxygen atom, in the skew forms, gives rise to an electron charge flux from the $\mathrm{C}=\mathrm{O}$ bonding region towards this atom, thus leading to a weakening of the $\mathrm{C}=\mathrm{O}$ bond in these conformers.

\subsection{Charge distribution analysis}

Table 2 shows the ab initio calculated Mulliken atomic charges and dipole moments for the various conformers of MCA

Following the general parttern for this kind of molecule [11,13-16], s-trans conformers have a considerably higher dipole moment than the corresponding $s$-cis forms. This result is a direct consequence of the relative orientation of the $\mathrm{C}=\mathrm{O}$ and $\mathrm{O}-\mathrm{C}\left(\mathrm{H}_{3}\right)$ bond dipoles in s-cis and s-trans conformers and, as referred to previously, have important energetic implications, favouring the $s$-cis forms (where the rough-space field interaction associated with the two bond dipoles is attractive). In addition, as previously predicted from vector addition of bond moments and MNDO semiempirical calculations [3], for a given configuration of the ester group, the syn conformer has a higher dipole moment than the skew form. The experimental dipole moment of MCA 
Table 2

6-31G* Mulliken atomic charges and dipole moments for the various conformers of methyl cyanoacetate

\begin{tabular}{|c|c|c|c|c|}
\hline & $\begin{array}{l}\text { Conformer } \\
s y n / s-c i s\end{array}$ & syn/s-trans & skew/s-cis & skew/s-trans \\
\hline & charge/e & & & \\
\hline $\mathrm{Cl}$ & 0.7995 & 0.8154 & 0.7981 & 0.8050 \\
\hline $\mathrm{O} 2$ & -0.5319 & -0.4947 & -0.5502 & -0.5095 \\
\hline $\mathrm{C} 3$ & -0.4641 & -0.5134 & -0.4513 & -0.4955 \\
\hline $\mathrm{O} 4$ & -0.6115 & -0.5966 & -0.5896 & -0.5857 \\
\hline C5 & -0.1932 & -0.2006 & -0.1944 & -0.2122 \\
\hline $\mathrm{H} 6$ & 0.1927 & 0.2222 & 0.1934 & 0.2172 \\
\hline H7 & 0.1927 & 0.1732 & 0.1896 & 0.2044 \\
\hline $\mathrm{H} 8$ & 0.1943 & 0.1732 & 0.1993 & 0.1684 \\
\hline C9 & 0.3390 & 0.3501 & 0.3202 & 0.3143 \\
\hline $\mathrm{H} 10$ & 0.2629 & 0.2552 & 0.2614 & 0.2506 \\
\hline H11 & 0.2629 & 0.2552 & 0.2682 & 0.2846 \\
\hline N12 & $\begin{array}{l}-0.4434 \\
\text { dipole moment/Debye }\end{array}$ & -0.4393 & -0.4447 & -0.4418 \\
\hline$|\mu|$ & 5.71 & 7.16 & 2.95 & 4.25 \\
\hline
\end{tabular}

${ }^{\mathrm{a}} e=1.6021892 \times 10^{-19} \mathrm{C} ; 1$ Debye $=3.336 \times 10^{-3} \mathrm{C} . \mathrm{m}$.

(in benzene solution) is $3.74 \mathrm{D}[3](1 \mathrm{D}=3.33564 \times$ $\left.10^{-3} \mathrm{C} . \mathrm{m}\right)$, a value that may be compared with the $\mathrm{ab}$ initio calculated values for the two most stable conformers (syn/s-cis: $5.71 \mathrm{D}$; skew/s-cis: 2.95 D).

From the calculated Mulliken atomic charges for the various conformers, the following correlations can be drawn:

1. For all conformers, the charge of the ester oxygen atom is predicted to be more negative than that of the carbonyl oxygen. This result follows the usual pattern previously observed for this kind of molecule and, as explained elsewhere [14], is essentially due to the larger $\pi$ electron population of the -O- atom when compared with that of the carbonyl oxygen, while the $\sigma$ electron population of these two oxygen atoms follows the inverse order.

2. For a given conformation of the $\mathrm{NC}-\mathrm{C}-\mathrm{C}=\mathrm{O}$ axis, the charge on the carbonyl oxygen atom is systematically more negative in the $s$-cis conformer than in the s-trans form. Such a result correlates with the prevalence in the first forms of the throughspace field interaction between the $\mathrm{C}=\mathrm{O}$ and $\mathrm{O}-$ $\mathrm{C}\left(\mathrm{H}_{3}\right)$ bond dipoles already mentioned. Moreover,

- this effect also explains the relative charges on $\mathrm{C} 5$ for $s$-trans and $s$-cis conformers, that are systematically less negative in the later.

3. For a given configuration of the ester group, the charge of the carbonyl oxygen atom is more negative in the skew than in the syn form. This can be considered as a consequence of the electron charge flux from the $\mathrm{C}=\mathrm{O}$ bonding region towards the carbonyl oxygen, that occurs upon syn $\rightarrow$ skew isomerisation, due to the presence, in the later form, of the positively charged methylene hydrogen atoms in the close vicinity of the carbonyl oxygen. Such a result reinforces the explanation given above to interpret the slight increase observed in the $\mathrm{C}=\mathrm{O}$ bond length upon syn $\rightarrow$ skew isomerisation.

4. Finally, the charges of the hydrogen atoms (in particular, $\mathrm{H} 10, \mathrm{H} 11, \mathrm{H} 7$ and $\mathrm{H} 8$ ) attain their less positive values in the syn/s-trans conformer, reflecting the strong electrostatic repulsion between these atoms in this form.

\subsection{Vibrational spectra}

MCA has 30 fundamental vibrations. In the case of the $\mathrm{C}_{\mathrm{s}}$ symmetry conformers ( $s y n$ forms), the normal modes will span the irreducible representations, $19 A^{\prime}$ $+11 A^{\prime \prime}$, while those of the non-symmetric skew forms ( $C_{1}$ point group) belong to the $A$ symmetry species. Hence, all vibrations are active in both Raman and infrared. Table 3 presents the definition of the internal symmetry coordinates used in this study. The 
Table 3

Definition of the internal symmetry coordinates used in normal coordinate analysis

\begin{tabular}{|c|c|c|c|}
\hline Coordinate & Symmetry $^{a}$ & Approximate description & Definition $^{b}$ \\
\hline$S_{1}$ & $A^{\prime}$ & $\nu \mathrm{C}=\mathrm{O}$ & $\nu \mathrm{C}=\mathrm{O}$ \\
\hline $\mathrm{S}_{2}$ & $A^{\prime}$ & $\nu \mathrm{C} 1-\mathrm{C} 3$ & $\nu \mathrm{Cl}-\mathrm{C} 3$ \\
\hline $\mathrm{S}_{3}$ & $A^{\prime}$ & $\nu \mathrm{Cl}-\mathrm{O}$ & $\nu \mathrm{C} 1-\mathrm{O}$ \\
\hline $\mathrm{S}_{4}$ & $A^{\prime}$ & $\nu \mathrm{C} 3-\mathrm{C} 9$ & $\nu \mathrm{C} 3-\mathrm{C} 9$ \\
\hline $\mathrm{S}_{5}$ & $A^{\prime}$ & $\nu \mathrm{C} \equiv \mathrm{N}$ & $\nu \mathrm{C} \equiv \mathrm{N}$ \\
\hline$S_{6}$ & $A^{\prime \prime}$ & $\nu \mathrm{CH}_{2}$ as & $(\nu \mathrm{C}-\mathrm{H} 10)-(\nu \mathrm{C}-\mathrm{H} 1 \mathrm{l})$ \\
\hline $\mathrm{S}_{7}$ & $A^{\prime}$ & $\nu \mathrm{CH}_{2} \mathrm{~S}$ & $(\nu \mathrm{C}-\mathrm{H} 10)+(\nu \mathrm{C}-\mathrm{H} 11)$ \\
\hline $\mathrm{S}_{8}$ & $A^{\prime}$ & $v \mathrm{O}-\mathrm{C} 5$ & $\nu \mathrm{O}-\mathrm{C} 5$ \\
\hline $\mathrm{S}_{9}$ & $A^{\prime}$ & $\nu \mathrm{CH}_{3} a s^{\prime}$ & $2(\nu \mathrm{C}-\mathrm{H} 8)-(\nu \mathrm{C}-\mathrm{H} 7)-(\nu \mathrm{C}-\mathrm{H} 6)$ \\
\hline$S_{10}$ & $A^{\prime \prime}$ & $\nu \mathrm{CH}_{3} a s^{\prime \prime}$ & $(\nu \mathrm{C}-\mathrm{H} 7)-(\nu \mathrm{C}-\mathrm{H} 6)$ \\
\hline $\mathrm{S}_{11}$ & $A^{\prime}$ & $\nu \mathrm{CH}_{3} s$ & $(\nu \mathrm{C}-\mathrm{H} 8)+(\nu \mathrm{C}-\mathrm{H} 7)+(\nu \mathrm{C}-\mathrm{H} 6)$ \\
\hline$S_{12}$ & $A^{\prime}$ & $\delta \mathrm{O}=\mathrm{C}-\mathrm{O}$ & $2(\delta \mathrm{O}=\mathrm{C}-\mathrm{O})-(\delta \mathrm{CC}=\mathrm{O})-(\delta \mathrm{CC}-\mathrm{O})$ \\
\hline$S_{13}$ & $A^{\prime}$ & $\delta \mathrm{CC}=\mathrm{O}$ & $(\delta \mathrm{CC}=\mathrm{O})-(\delta \mathrm{CC}-\mathrm{O})$ \\
\hline $\mathrm{S}_{14}$ & $A^{\prime}$ & $\delta \mathrm{C}-\mathrm{O}-\mathrm{C}$ & $\delta \mathrm{C}-\mathrm{O}-\mathrm{C}$ \\
\hline$S_{15}$ & $A^{\prime}$ & $\delta \mathrm{CH}_{3} a s^{\prime}$ & $2(\delta \mathrm{H} 6-\mathrm{C}-\mathrm{H} 7)-(\delta \mathrm{H} 6-\mathrm{C}-\mathrm{H} 8)-(\delta \mathrm{H} 7-\mathrm{C}-\mathrm{H} 8)$ \\
\hline$S_{16}$ & $A^{\prime \prime}$ & $\delta \mathrm{CH}_{3} a s^{\prime \prime}$ & $(\delta \mathrm{H} 6-\mathrm{C}-\mathrm{H} 8)-(\delta \mathrm{H} 7-\mathrm{C}-\mathrm{H} 8)$ \\
\hline $\mathrm{S}_{17}$ & $A^{\prime}$ & $\delta \mathrm{CH}_{3} \mathrm{~S}$ & $\begin{array}{l}(\delta \mathrm{H} 6-\mathrm{C}-\mathrm{H} 8)+(\delta \mathrm{H} 7-\mathrm{C}-\mathrm{H} 8)+(\delta \mathrm{H} 6-\mathrm{C}-\mathrm{H} 7)-(\delta \mathrm{O}-\mathrm{C}-\mathrm{H} 8)- \\
(\delta \mathrm{O}-\mathrm{C}-\mathrm{H} 7)-(\delta \mathrm{O}-\mathrm{C}-\mathrm{H} 6)\end{array}$ \\
\hline $\mathrm{S}_{18}$ & $A^{\prime}$ & $\gamma \mathrm{CH}_{3}^{\prime}$ & $2(\delta \mathrm{O}-\mathrm{C}-\mathrm{H} 8)-(\delta \mathrm{O}-\mathrm{C}-\mathrm{H} 7)-(\delta \mathrm{O}-\mathrm{C}-\mathrm{H} 6)$ \\
\hline $\mathrm{S}_{19}$ & $A^{\prime \prime}$ & $\gamma \mathrm{CH}_{3}^{\prime \prime}$ & $(\delta \mathrm{O}-\mathrm{C}-\mathrm{H} 7)-(\delta \mathrm{O}-\mathrm{C}-\mathrm{H} 6)$ \\
\hline$S_{20}$ & $A^{\prime}$ & $\gamma \mathrm{CH}_{2}$ & $\begin{array}{l}5(\delta \mathrm{H} 10-\mathrm{C}-\mathrm{H} 11)-(\delta \mathrm{CCC})-(\delta \mathrm{Cl}-\mathrm{C} 3-\mathrm{H} 10)-(\delta \mathrm{C} 1-\mathrm{C} 3-\mathrm{H} 11)- \\
(\delta \mathrm{C} 9-\mathrm{C} 3-\mathrm{H} 10)-(\delta \mathrm{C} 9-\mathrm{C} 3-\mathrm{H} 11)\end{array}$ \\
\hline$S_{21}$ & $A^{\prime}$ & $\omega \mathrm{CH}_{2}$ & $(\delta \mathrm{C} 1-\mathrm{C} 3-\mathrm{H} 10)+(\delta \mathrm{C} 1-\mathrm{C} 3-\mathrm{H} 11)-(\delta \mathrm{C} 9-\mathrm{C} 3-\mathrm{H} 10)-(\delta \mathrm{C} 9-\mathrm{C} 3-\mathrm{H} 1 \mathrm{l})$ \\
\hline $\mathrm{S}_{22}$ & $A^{\prime \prime}$ & tw $\mathrm{CH}_{2}$ & $\begin{array}{l}(\delta \mathrm{C} 1-\mathrm{C} 3-\mathrm{H} 10)-(\delta \mathrm{C} 1-\mathrm{C} 3-\mathrm{H} 11)-(\delta(\mathrm{C} 9-\mathrm{C} 3-\mathrm{H} 10)+ \\
(\delta \mathrm{C} 9-\mathrm{C} 3-\mathrm{H} 11)\end{array}$ \\
\hline $\mathrm{S}_{23}$ & $A^{\prime \prime}$ & $\gamma \mathrm{CH}_{2}$ & $(\delta \mathrm{C} 1-\mathrm{C} 3-\mathrm{H} 10)-(\delta \mathrm{C} 1-\mathrm{C} 3-\mathrm{H} 11)+(\delta \mathrm{C} 9-\mathrm{C} 3-\mathrm{H} 10)-(\delta \mathrm{C} 9-\mathrm{C} 3-\mathrm{H} 11)$ \\
\hline$S_{24}$ & $A^{\prime}$ & $\delta \mathrm{CCC}$ & $\begin{array}{l}4(\delta C C C)-(\delta \mathrm{Cl}-\mathrm{C} 3-\mathrm{H} 10)-(\delta \mathrm{C} 1-\mathrm{C} 3-\mathrm{H} 11)-(\delta \mathrm{C} 9-\mathrm{C} 3-\mathrm{H} 10)- \\
(\delta \mathrm{C} 9-\mathrm{C} 3-\mathrm{H} 11)\end{array}$ \\
\hline$S_{2 S}$ & $A^{\prime}$ & $\delta \mathrm{CC} \equiv \mathrm{N}$ & $\delta \mathrm{CC} \equiv \mathrm{N}$ \\
\hline $\mathrm{S}_{26}$ & $A^{\prime \prime}$ & $\gamma \mathrm{C}=\mathrm{O}$ & $\gamma \mathrm{C}=\mathrm{O}$ \\
\hline$S_{27}$ & $A^{\prime \prime}$ & $\gamma \mathrm{CC} \equiv \mathrm{N}$ & $\delta \mathrm{CC} \equiv \mathrm{N}$ \\
\hline $\mathrm{S}_{28}$ & $A^{\prime \prime}$ & $\tau \mathrm{C} 1-\mathrm{O}$ & $\pi \mathrm{Cl}-\mathrm{O}$ \\
\hline$S_{29}$ & $A^{\prime \prime}$ & $\tau \mathrm{Cl}-\mathrm{C} 3$ & $\tau \mathrm{Cl}-\mathrm{C} 3$ \\
\hline $\mathrm{S}_{30}$ & $A^{\prime \prime}$ & $\tau \mathrm{O}-\mathrm{CH}_{3}$ & $7 \mathrm{O}-\mathrm{CH}_{3}$ \\
\hline
\end{tabular}

${ }^{\text {a }}$ Symmetry refers strictly to $\mathrm{C}_{\mathrm{s}}$ conformers. For the non-symmetric $\mathrm{C}_{1}$ forms, all coordinates belong to the $A$ symmetry species.

${ }^{b}$ Normalisation constants are not given here; they are chosen as $\mathrm{N}=\left(\Sigma \mathrm{C}_{\mathrm{i}}^{2}\right)^{-1 / 2}$, where $\mathrm{C}_{\mathrm{i}}$ are the coefficients of the individual valence coordinates. Vibrations: $\nu$, bond stretching; $\delta$, bending; $\omega$, wagging; tw, twisting; $\gamma$, rocking; $\tau$, torsion; as., asymmetric; $s$., symmetric.

observed and theoretically predicted spectra are shown in Figs. 2-6, and the vibrational assignments summarised in Table 4 . Table 5 presents the results of the theoretical vibrational calculations for the nonobserved s-trans conformers. All the calculated frequencies shown correspond to scaled values, obtained by multiplying the ab initio values by a single scale factor $(0.9)$. While very simple, this scaling procedure preserves the potential energy distributions (PEDs) as they emerge from the ab initio calculations, thus having an important advantage over the more elaborate force field scaling procedures that use more than one scale factor, that usually give rise to important PED distortions from the ab initio calculated values.

\subsection{Region above $1700 \mathrm{~cm}^{-1}$}

This is the spectral region where the $\nu \mathrm{C}-\mathrm{H}$ (five modes: $\nu \mathrm{CH}_{2}$ as., $\nu \mathrm{CH}_{2}$ s., $\nu \mathrm{CH}_{3} s$. and the two $\nu \mathrm{CH}_{3}$ as. vibrations), $\nu \mathrm{C} \equiv \mathrm{N}$ and $\nu \mathrm{C}=\mathrm{O}$ stretching modes occur.

The assignments of both $\nu \mathrm{C} \equiv \mathrm{N}$ and $\nu \mathrm{C}=\mathrm{O}$ are straightforward, since these modes give rise to bands in well defined and practically clear spectral regions. 


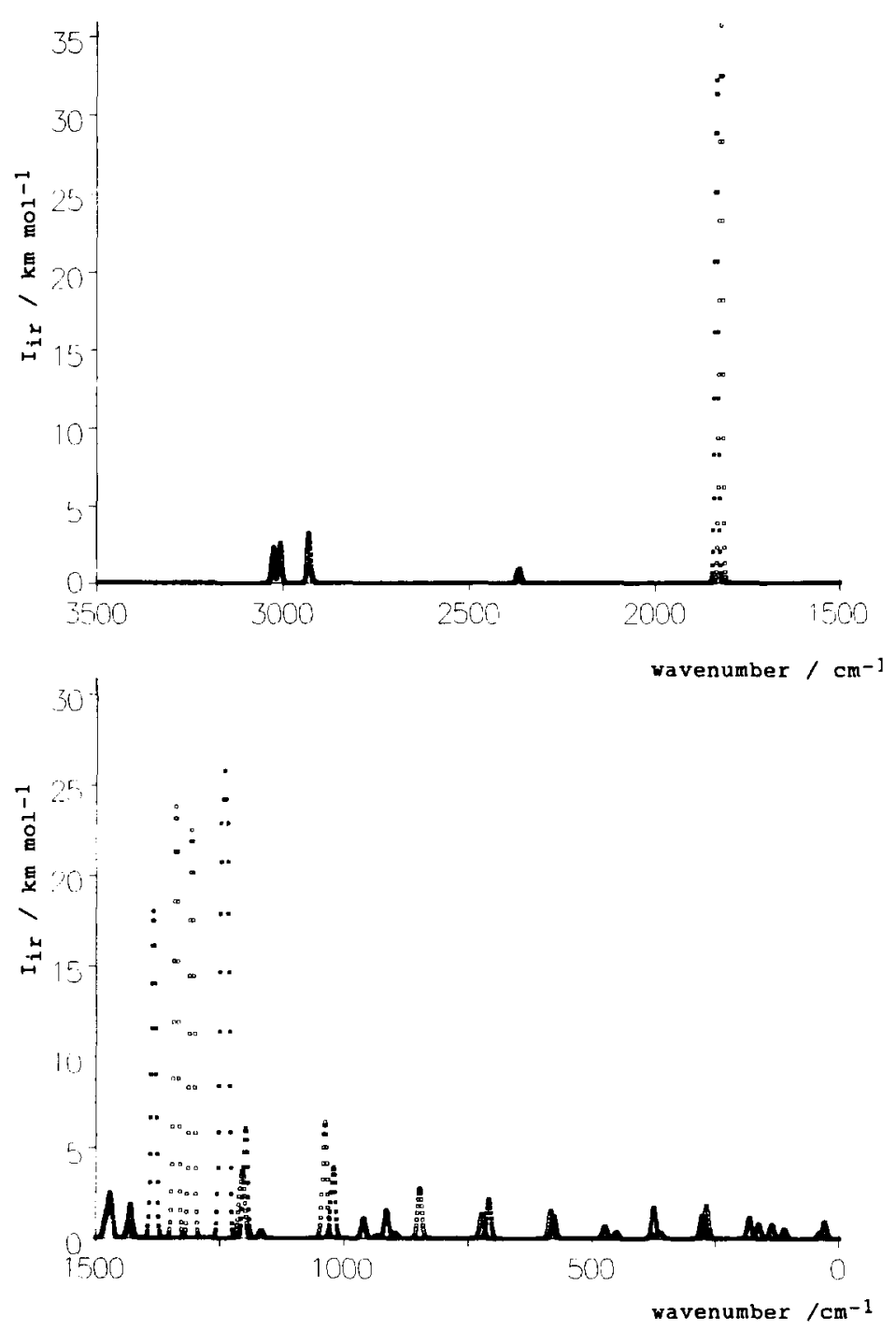

Fig. 2. 6-31G* calculated IR spectra of the two spectroscopically observed conformers of MCA: $\square$ syn/scis; $\square$ skew/s-cis. The calculated intensities of the bands due to the syn/s-cis conformer are multiplied by the factor 1.12 to account for the relative population of the two conformers at room temperature (see text). All gaussian functions used to simulate the bands are arbitrarily chosen to have a half band width equal to $10 \mathrm{~cm}^{-1}$

The calculations predict that these vibrations should appear at slightly higher frequencies in the syn/s-cis conformer, but, for the liquid sample, it was not possible to resolve the $\nu \mathrm{C}=\mathrm{O}$ band into the two components originated in individual conformers. However, in consonance with this result, the $\nu \mathrm{C}=\mathrm{O}$ band blueshifts upon crystallisation $\left(1762 \mathrm{~cm}^{-1}\right)$, clearly reflecting the fact that, in this later situation, only the more polar syn conformer exists. On the other hand, $\nu \mathrm{C} \equiv \mathrm{N}$ appears as an overlapping doublet of bands, whose temperature dependence enables us to assign the higher frequency conponent to the skew form. Despite the fact that the order of appearance of the bands is not the same as predicted by the calculations, this assignment is reinforced by the crystalline state data, since despite several bands which appear in the corresponding spectral region due to overtone or/and combination modes, the main band 
a)

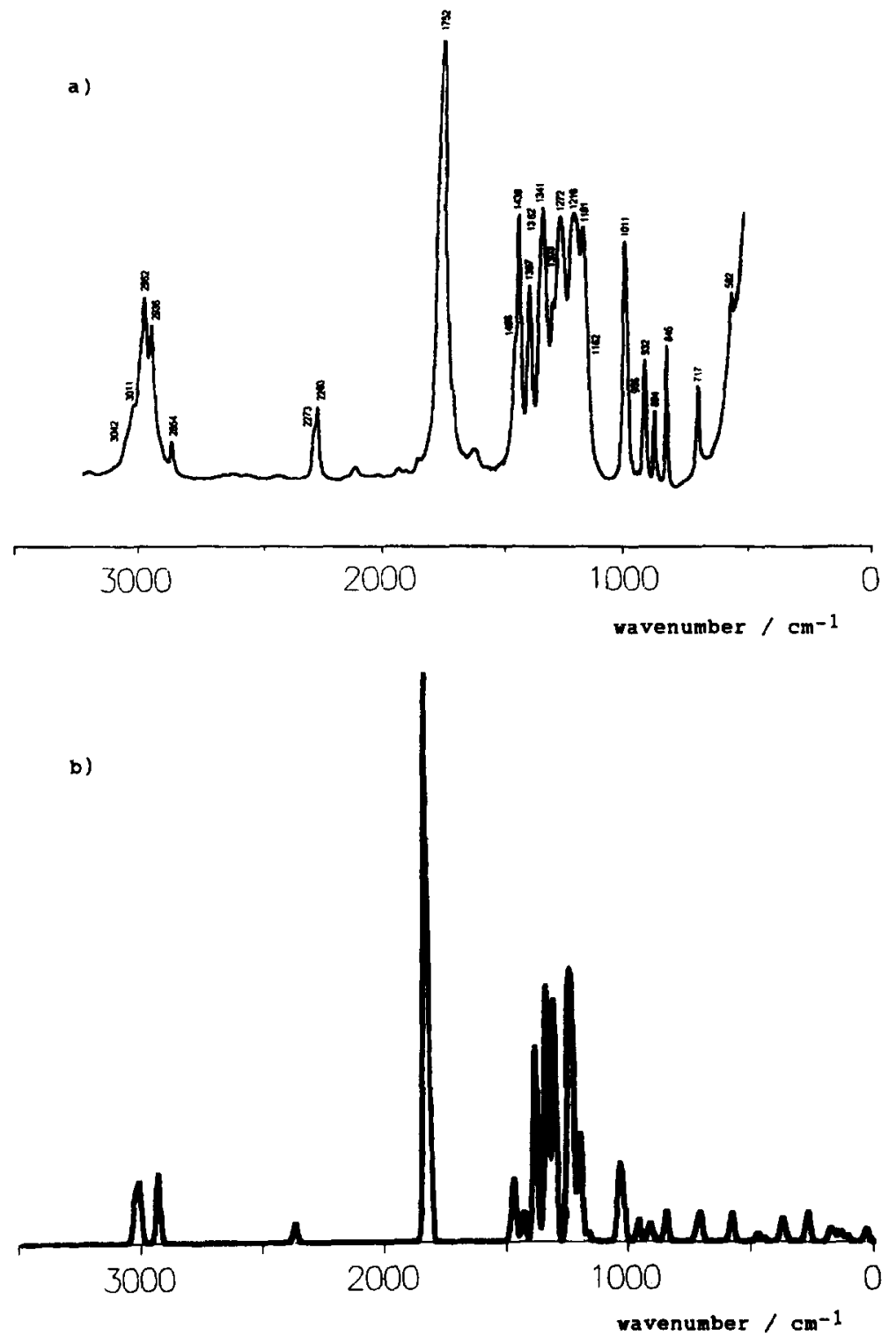

Fig. 3. (a) Experimental FT-IR spectrum of liquid MCA at room temperature. (b) 6-31G* predicted IR spectrum of MCA obtained by co-adding the calculated IR spectra for individual conformers (svn/s-cis and skew/s-cis forms; see Fig. 2). All gaussian functions used to simulate the bands are arbitrarily chosen to have a half band width equal to $30 \mathrm{~cm}^{-1}$.

(that must be assigned to $\nu \mathrm{C} \equiv \mathrm{N}$ in the $s y n$ form) appears at $2259 \mathrm{~cm}^{-1}$, being coincident with the lowest frequency band observed in the liquid phase.

In the case of the $\nu \mathrm{C}-\mathrm{H}$ modes, the calculations predict that: (i) with the single exception of $\nu \mathrm{CH}_{2}$ $a s$, that should appear at a slightly higher frequency in the skew form, all modes have similar frequencies in the two conformers; (ii) all vibrations should be considerably intense in Raman, while the two $\nu \mathrm{CH}_{2}$ modes (in particular $\nu \mathrm{CH}_{2}$ as.) should have low IR intensities. In consonance with the theoretical predictions, five Raman bands could be observed in this spectral region and assigned to the different $\nu \mathrm{C}-\mathrm{H}$ modes, also taking into consideration the fact that 


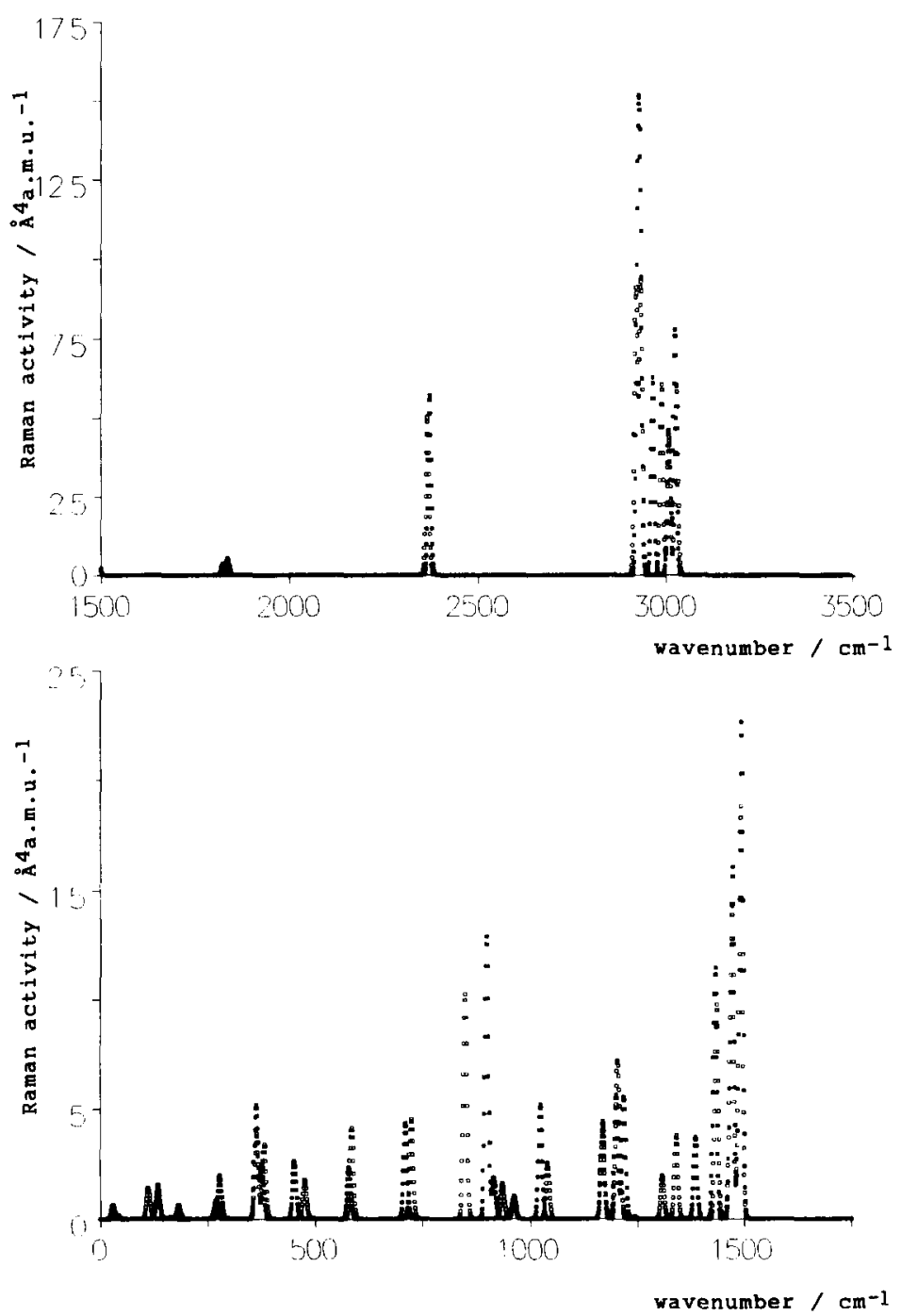

Fig. 4. 6-31G* calculated Raman spectra of the two spectroscopically observed conformers of MCA: syn/scis; $\square$ skew/s-cis. The calculated intensities of the bands due to the syn/s-cis conformer are multiplied by the factor 1.12 to account for the relative population of the two conformers at room temperature (see text). All gaussian functions used to simulate the bands are arbitrarily chosen to have a half band width equal to $10 \mathrm{~cm}^{-1}$.

$\nu \mathrm{CH}_{2}$ as. in the skew conformer must appear at a considerably higher frequency than in the syn form (Table 4). In turn, the IR spectrum shows only four bands in this spectral region that can be assigned to fundamental vibrations (the $2854 \mathrm{~cm}^{-1}$ band, previously wrongly ascribed to $\nu \mathrm{CH}_{2} s$. [2], was here assigned to the first overtone of the $\delta \mathrm{CH}_{3} s$. bending vibration intensified by Fermi interaction with the
${ }_{\nu} \mathrm{CH}_{3} s$. stretching mode, on the basis of the conclusions of previous systematic studies of this effect in methyl esters [21]).

\section{5. $1700-1000 \mathrm{~cm}^{-1}$ region}

In this spectral region, the $\mathrm{CH}_{3}$ bending and rocking modes, methylene scissoring, wagging and 

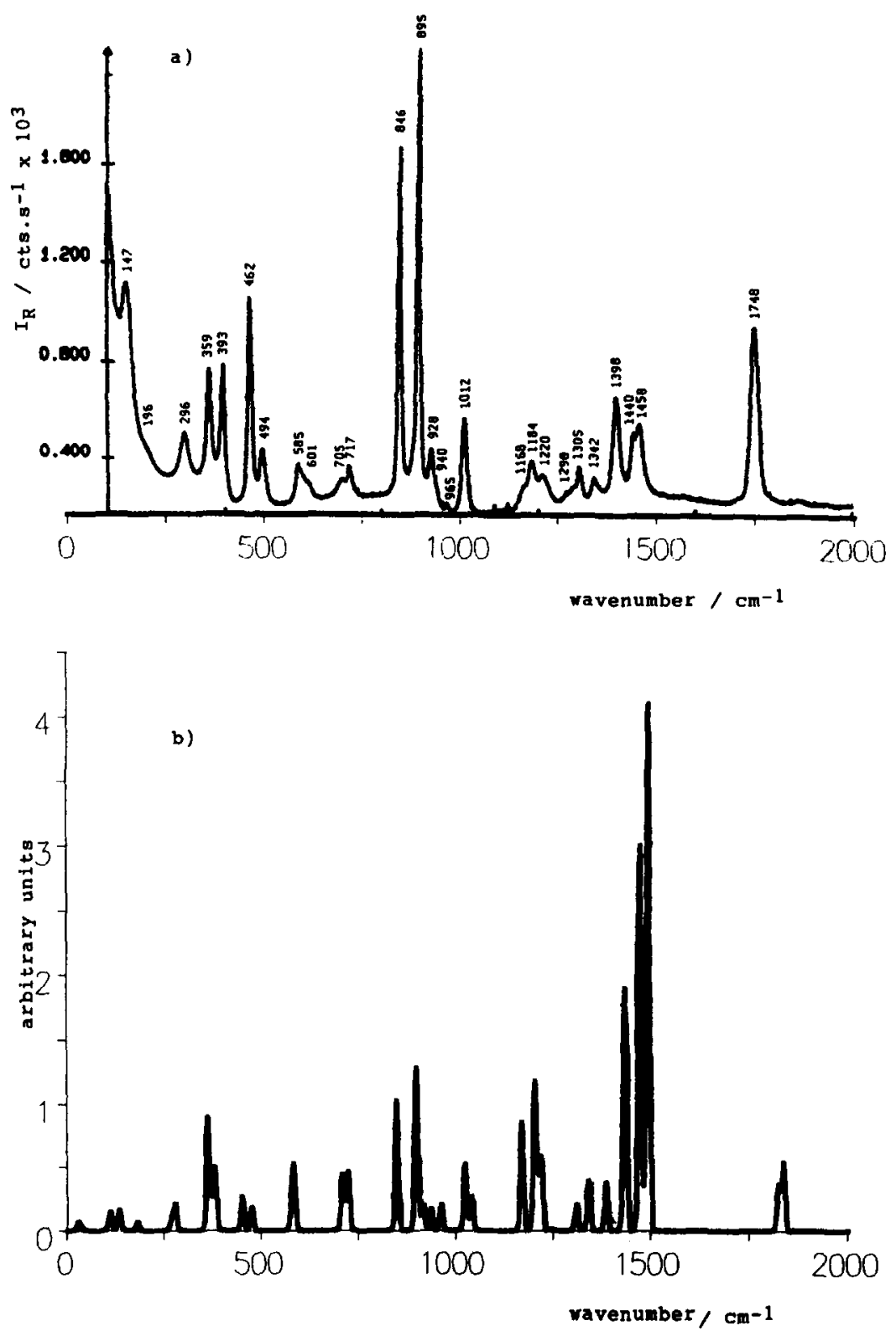

Fig. 5. (a) Experimental Raman spectrum of liquid MCA ( 100-2000 $\mathrm{cm}^{-1}$ region) at room temperature. (b) 6-31G* predicted IR spectrum of MCA (some region) obtained by co-adding the calculated Raman spectra for individual conformers (syn/s-cis and skew/s-cis forms) shown in Fig. 4.

twisting vibrations and the two carbon-oxygen single bonds' stretching modes ( $\nu \mathrm{C} 1-\mathrm{O}$ and $\nu \mathrm{O}-\mathrm{C} 5)$ appear.

When compared with the previously proposed assignments [2], the assignments now made for the bands occurring in this spectral region agree in with concern to the $\delta \mathrm{CH}_{3}$ bending modes, $\nu \mathrm{Cl}-\mathrm{O}$ and $\nu \mathrm{O}$ $\mathrm{C} 5$, though in the case of the two $\nu \mathrm{C}-\mathrm{O}$ vibrations the precise characterisation of the modes was not given in the previous study (instead, a general designation "skeletal stretching" was used [2]). On the other 

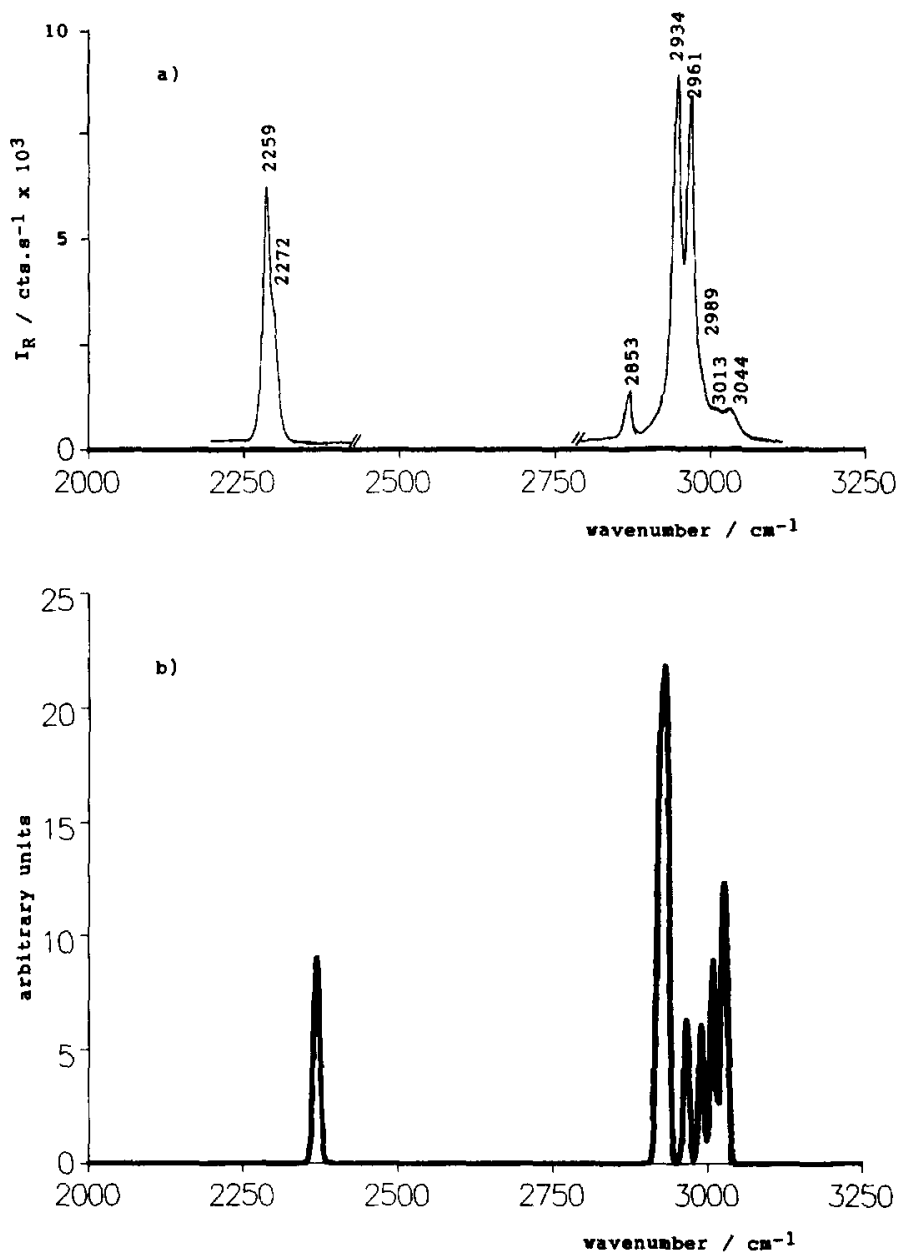

Fig. 6. (a) Experimental Raman spectrum of liquid MCA (2000-3250 $\mathrm{cm}^{-1}$ region) at room temperature. (b) 6-31G* predicted IR spectrum of MCA (some region) obtained by co-adding the calculated Raman spectra for individual conformers (syn/s-cis and skew/s-cis forms) shown in Fig. 4.

hand, the remaining modes are now reassigned taking into consideration the results of the theoretical predictions (Table 4). The following points deserve further comment:

1. Both in the IR and Raman spectra of the liquid MCA, two bands appear in this spectral region that originate in the skew conformer, thus increasing their relative intensities upon raising the temperature and being absent in the spectra of the crystal. These bands correspond to the $\omega \mathrm{CH}_{2}$ (IR, $1341 \mathrm{~cm}^{-1}$; Raman, $1342 \mathrm{~cm}^{-1}$ ) and $\nu \mathrm{Cl}-\mathrm{O}\left(\mathrm{IR}, 1272 \mathrm{~cm}^{-1}\right.$; Raman, $1298 \mathrm{~cm}^{-1}$ )modes;
2. All the other bands appearing in this spectral region have similar contributions from both conformers, except the relatively broad IR band at $1216 \mathrm{~cm}^{-1}$ (that has its Raman counterpart appearing at $1220 \mathrm{~cm}^{-1}$ ), which is essentially due to the twCH $\mathrm{CH}_{2}$ mode of the syn conformer. This later band is predicted by the calculations to be considerably more intense in IR than observed (Table 4) and it appears as a doublet of bands at 1218 and $1203 \mathrm{~cm}^{-1}$ in the IR spectrum of the crystalline sample. Thus, it seems that the broad band of the liquid phase IR spectrum due to the $\mathrm{twCH}_{2}$ fundamental of the $s y n$ conformer corresponds in 


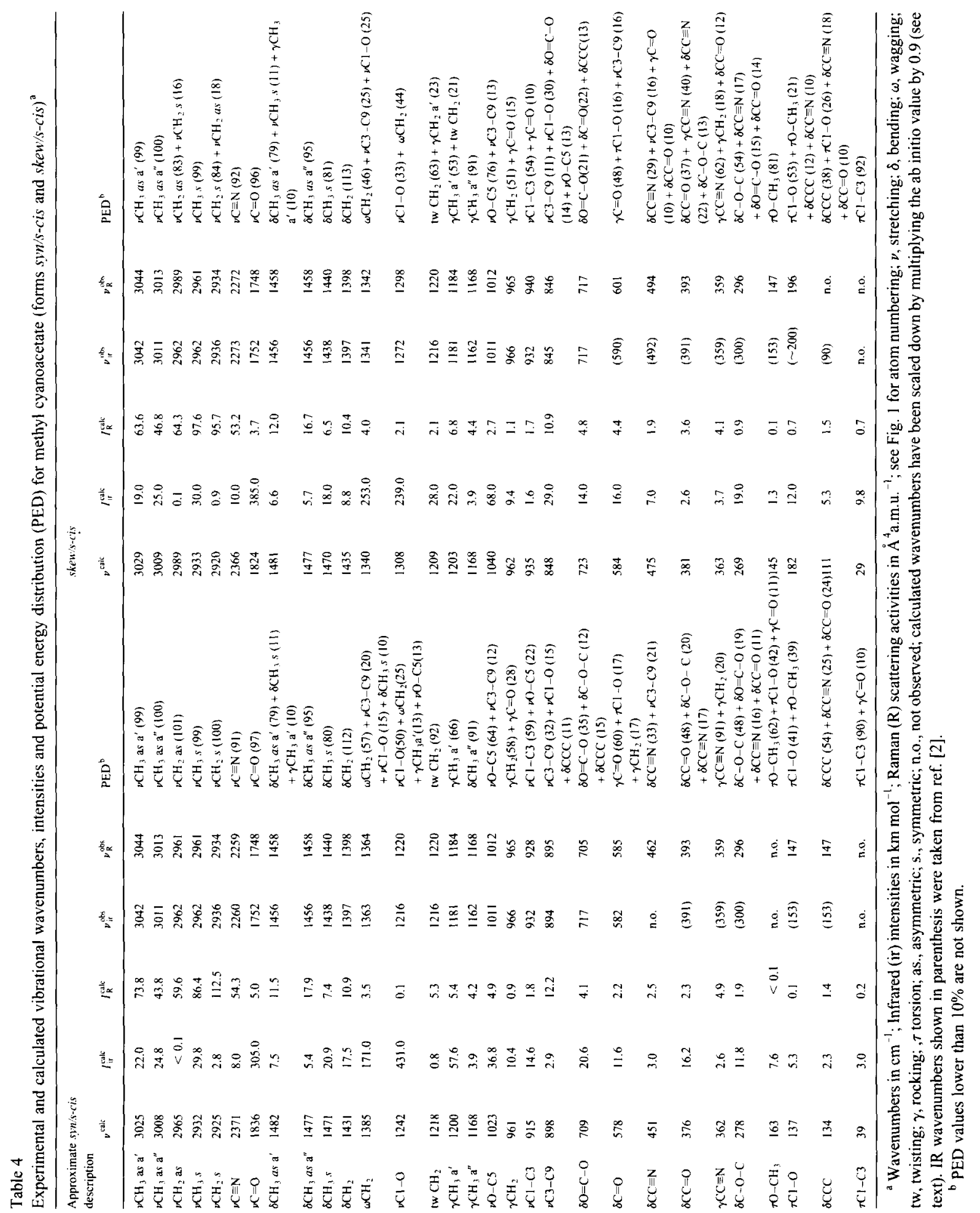




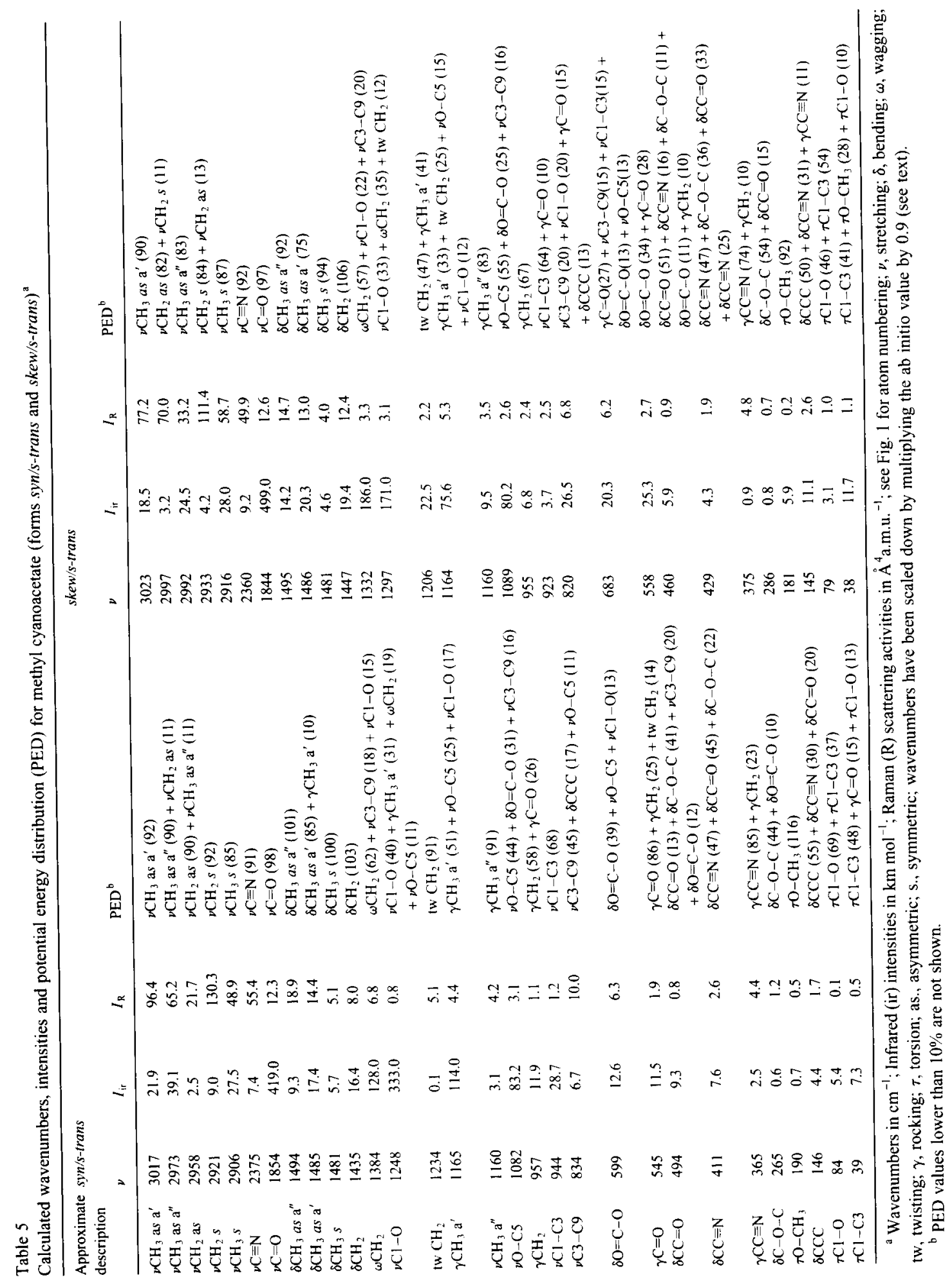


fact to an unresolved Fermi doublet, most probably resulting from the interaction with the $\nu \mathrm{O}-\mathrm{C} 5+$ $\delta \mathrm{C}-\mathrm{O}-\mathrm{C}$ combination mode. This interpretation was considered in the simulation of the IR predicted spectrum of MCA shown in Fig. 3, where an unresolved doublet of bands due to this interaction, each one with half of the total intensity calculated for the $\mathrm{wwCH}_{2}$ IR band, has been plotted instead of a single band. Indeed, such procedure enables us to attain a much better fit between the predicted and experimentally observed IR spectra;

3 . The results of the normal coordinate analysis indicate that the $\omega \mathrm{CH}_{2}$ and $\nu \mathrm{Cl}-\mathrm{O}$ vibrations are considerably mixed, in particular in the case of the non-symmetric skew conformer. On the other hand, the $\nu \mathrm{O}-\mathrm{C} 5$ stretching mode, and all the methyl bending and rocking modes have a clear prevalence of a single coordinate (this is particularly evident in the case of the syn form, Table 4);

4. The calculations predict $\nu \mathrm{Cl}-\mathrm{O}$ to occur at higher frequencies than observed $\left(\Delta \nu \mathrm{Cl}-\mathrm{O}_{\text {(cal-exp) }}\right.$ $\sim 30 \mathrm{~cm}^{-1}$ ). Indeed, the same trend can also be noticed for both $\nu \mathrm{C} \equiv \mathrm{N} \quad\left(\Delta \nu \mathrm{C} \equiv \mathrm{N}_{\text {(cal-exp) }}\right.$ $\left.\sim 100 \mathrm{~cm}^{-1}\right) \quad$ and $\quad \nu \mathrm{C}=\mathrm{O} \quad\left(\Delta \nu \mathrm{C}=\mathrm{O}_{\text {(cal-exp) }}\right.$ $\sim 80 \mathrm{~cm}^{-1}$ ). This is a direct consequence of the intermolecular interactions present in the condensed phases, that affect mainly the more polarised bonds (the theoretical data assumes the molecule isolated in the vacuum), and these results follow the trend previously reported for similar studies in other carboxylic compounds $[1,13,15]$. It must be stressed that these are in fact the three vibrational modes that have their frequencies most overestimated by calculations, and that, as a trend, this overestimation is slightly larger for the more polar syn conformer (Table 4).

\subsection{Region below $1000 \mathrm{~cm}^{-1}$}

In this spectral region the $\gamma \mathrm{CH}_{2}$ rocking mode, the two $\nu \mathrm{C}-\mathrm{C}$ stretching vibrations, and all skeletal bending and torsional modes appear.

In the Raman spectrum of liquid MCA it was possible to observe in this spectral region five bands that are due to the skew conformer: the intense and well resolved band at $846 \mathrm{~cm}^{-1}$ (IR: $845 \mathrm{~cm}^{-1}$ ), assigned to $\nu \mathrm{C} 3-\mathrm{C} 9$, the bands at 717,601 and $494 \mathrm{~cm}^{-1}$, here assigned to $\delta \mathrm{O}=\mathrm{C}-\mathrm{O}, \gamma \mathrm{C}=\mathrm{O}$ and $\delta \mathrm{C}-\mathrm{C} \equiv \mathrm{N}$, respectively, and the shoulder at $196 \mathrm{~cm}^{-1}$, tentatively assigned to the $\tau \mathrm{Cl}-\mathrm{O}$ torsional mode. The assignments now made for this spectral region, which are fully supported by the theoretical results, are considerably different and improve significantly the tentative assignments made in ref. [2].

Using the temperature dependence of the relative intensities of the pairs of bands at $894 / 845 \mathrm{~cm}^{-1}$ (IR) and 895 / $846 \mathrm{~cm}^{-1}$ and $462 / 494 \mathrm{~cm}^{-1}$ (Raman), over the temperature range $298-333 \mathrm{~K}$ (above $333 \mathrm{~K}$ the compound starts to decompose), an average value of $2.0 \pm 0.2 \mathrm{~kJ} \mathrm{~mol}^{-1}$ for

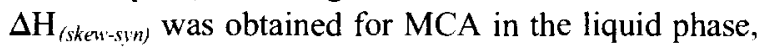
corresponding to a relative $s y n /$ skew population ratio, at room temperature, equal to 1.12 . The experimentally measured enthalpy difference between the two conformers (that lies in between the previously reported values: $4.06 \mathrm{~kJ} \mathrm{~mol}^{-1}$ [2]; $1.46 \mathrm{~kJ} \mathrm{~mol}^{-1}$ [3]), is higher than the conformer energy difference calculated for the isolated molecule situation $\left(\Delta E_{(s k e t-s i n)}=0.94 \mathrm{~kJ} \mathrm{~mol}^{-1}\right)$, a result that is consistent with an additional stabilisation in the condensed phase of the more polar syn conformer.

\section{Acknowledgements}

The authors acknowledge the PRAXIS XXI, Junta Nacional de Investigação Científica e Tecnológica (J.N.I.C.T.) and FEDER for financial support to this work, which has been held under the scope of the PRAXIS XXI 2/2.1/QUI/412/94 research project.

\section{References}

[1] J.M.F. Neta, Estudo Estrutural e Espectroscópico de Compostos Carbonílicos $\alpha$-ciano-substituídos, Departamento de Química, Universidade de Coimbra, Internal Report 1997 (and references therein).

[2] S.W. Charles, G.I.L. Jones, N.L. Owen, J. Chem. Soc. Faraday Trans II 69 (1973) 1454.

[3] C. Maury, J. Petrissans, J. Mol. Struct. 246 (1991) 267

[4] R. Das, S. Chattopadhayay, G.S. Kastha, Indian J. Phys. 53B (1979) 297.

[5] W.J. Hehre, R. Ditchefield, J.A. Pople, J. Chem. Phys. 56 (1972) 2257

[6] M.J. Frisch, G.W. Trucks, H.B. Schlegel, P.M.W. Gill, B.G. Johson, M.W. Wong, J.B. Foresman, M.A. Robb, M. Head-Gordon, E.S. Replogle, R. Gomperts, J.L. Andres, 
K. Raghavachari, J.S. Binkley, C. Gonzalez, R.L. Martin, D.J. Fox, D.J. Defrees, J Baker, J.J.P. Stewart, J.A. Pople, GAUSSIAN 92/DFT (Revision G.2), Gaussian Inc., Pittsburgh PA, 1993.

[7] H.B. Schlegel, Ph.D. Thesis, Queen's University, Kingston, Ontario, Canada, 1975

[8] R. Fausto, TRANSFORMER (version 2.0), Departamento de Quimica, Universidade de Coimbra, Portugal, 1997.

[9] M.D.G. Faria, R. Fausto, BUILD-G and VIBRAT, Departamento de Química, Universidade de Coimbra, Portugal, 1990 (These programs incorporate several routines from programs GMAT and FPERT, H. Fuher, V.B. Kartha, K.G. Kidd, P.J. Krueger, H.H. Mantsch, Natl. Res. Council Can. Bull. 15(1976) 1.

[10] J.J.C. Teixeira-Dias, R. Fausto, J. Mol. Struct. 144 (1986) 199.

[11] R. Fausto, J.J.C. Teixeira-Dias, J. Mol. Struct. (Theochem.) $150(1987) 381$.
[12] R. Fausto, J.J.C. Teixeira-Dias, J. Mol. Struct. 144 (1986) 215 , $225,241$.

[13] A. Kulbida. R. Fausto, J. Chem. Soc. Faraday Trans. 89 (1993) 4257.

[14] R. Fausto, J. Mol. Struct. (Theochem.) 315 (1994) 123.

[15] R. Fausto, A. Kulbida, O. Schrems, J. Chem. Soc. Faraday Trans. 91 (1995) 3755.

[16] R. Fausto, F.P.S.C. Gil, J.J.C. Teixeira-Dias, J. Chem. Soc. Faraday Trans. 89 (1993) 3235.

[17] A. Kulbida, A. Nosov, J. Mol. Struct. 265 (1992) 17.

[18] P.J. Tonge, V.E. Andersson, R. Fausto, M. Kim, M. PusztayCarey, P.R. Carey, Biospectroscopy 1 (1995) 387.

[19] L.A.E. Batista de Carvalho, J.J.C. Teixeira-Dias, R. Fausto, J. Mol. Struct. (Theochem.) 208 (1990) 109.

[20] R. Fausto, Ph.D. Thesis, Departamento de Química, Universidade de Coimbra, Coimbra, Portugal, 1988.

[21] J.C. Lavalley, N. Sheppard, Spectrochim. Acta 28A (1972) 2091. 